\title{
The Teaching of Optics in Schools
}

\begin{abstract}
$\mathrm{A}^{\mathrm{T}}$
$\mathrm{T}$ the annual meeting in London of the Science Masters' Association, a large body of schoolmasters met to consider the findings of the committee convened by the Council of the Physical Society to report upon various matters connected with the teaching of geometrical optics. The discussion was opened by Mr. G. N. Pingriff, of Merchant Taylors' School, a member of the committee, who gave a brief summary of the report in so far as it is concerned with teaching in schools, and confining himself chiefly to the question of signs of distances involved in lens and mirror calculations and experiments.

In most advanced work, and invariably in technical opties, it is customary to call a converging lens positive and a diverging lens negative, whereas the opposite custom is usually followed in school teaching and in nearly all school text-books : in these, the rule which has become established is that distances should be measured from the lens or mirror, and if measured in the direction of the incident light they should be considered negative. The committee had carefully considered this and a number of other conventions used by writers of various advanced text-books, and had unanimously agreed that it was desirable that all teachers should henceforward adopt one or the other of the two schemes given below. It had not been possible to reach unanimity in recommending one only, though both of the schemes advocated agree in making the focal length of a converging lens positive and hence in reversing the school system. The report also emphasised the desirability of teaching lens theory before that of curved mirrors, and of introducing the idea of the power of a lens at an early stage.
\end{abstract}

The alternative schemes recommended were: (a) to use a Cartesian frame of reference in which the positive direction is the initial direction of progress of the incident light, and $(b)$ to measure all distances along the rays of light, giving a positive sign to paths which the light has actually traversed and a negative to distances only traversed virtually.

The opener of the discussion explained the exact implication of each of these systems and the advantages to be derived from a change from the present school usage, after which numerous other speakers gave their opinions, and in some cases experiences of work done, on one or other of the new schemes. All speakers were definitely in favour of making a change but here again there was no unanimity as to which of the alternatives should be adopted, though on the whole the majority of the speakers seemed to be in favour of the second, that is, $(b)$ above. The advantage of this scheme which appealed to many speakers was that it leads to the same simple general formula for mirrors and lenses. On the other hand, it was recognised that the first scheme could be adopted with a less radical change of procedure, and also that it is largely used in the teaching of applied optics. The main view expressed by the different speakers was emphatically confirmed by an informal show of hands at the end of the discussion, there being a very large majority of members, all of whom were schoolmasters having practical experience of the matters under consideration, in favour of a change from the present school practice. It was pointed out that the only further requirement to enable these views to be put into practice is the supply of suitable elementary text-books. G. N. P.

\section{School Certificate Biology}

$\mathrm{I}^{\mathrm{T}}$ is probably safe to say that there has been in recent years a greater increase in the number of candidates taking biology in the School Certificate Examination than in any other subject. It is therefore not surprising that a short time ago the committee of the Science Masters' Association appointed a sub-committee to draw up a syllabus in biology which represented as far as possible the views of all its members. The preliminary draft of this syllabus appeared in the December issue of the School Science Review, and members were asked to communicate their criticisms to the secretary of the sub-committee. At the recent annual meeting of the Association in London, two discussions on this subject were arranged. These were well attended and the views of members on a number of debatable points were heard. The general committee of the Association now intends to invite representations of all examining boards to meet a few of its members who have drawn up the syllabus. It is hoped that the examining boards will co-operate in this respect, and in some cases revise their syllabuses in accordance with the views of those who are actually teaching the subject.
The aim of the sub-committee has been to produce a syllabus in which general biological principles are established rather than a mass of detailed facts. It is quite clear that in working to many of the existing syllabuses there is only time in teaching to work through a number of types. For this reason the number of types to be studied has been reduced, and, although individuals may be sorry that their 'pet' organism has not been included, it is absolutely essential that the syllabus should be much shorter than most of the existing ones. The experience of examiners has shown quite clearly that while eandi. dates may be able to describe the arterial system of a frog or of a mammal or the structure of a stem, for example, in detail, their answers to general questions are very poor.

The first section of the syllabus deals entirely with general biology. No definite types are mentioned, choice of examples for illustration being left in the hands of the teacher. It is possible, if the time avail. able for the subject is short, to use only as illustra. tions the types mentioned in the remainder of the syllabus, but it is hoped that a wider view will be 
taken-but not expected by the examiner. From the criticisms received and from the discussions held it is obvious that teachers are almost unanimous in preferring the mammal as the type of vertebrate to study rather than the frog. The heading to this part now reads as follows :

"The general elementary structure of a mammal as illustrated by the following scheme. (It is suggested that the rabbit or guinea pig be used for most of this work, including demonstration dissections, but it is important that reference should also be made to Man and that the frog should be used occasionally for experimental purposes.)"

The other zoological types included are Hydra, where the principle of differentiation and specialisation of parts of a multicellular organism can be well seen, an earthworm, chiefly for its habits and economic importance, certain insects, for their life-histories only, and Amoeba or Paramecium, excluding, of course, details of conjugation processes in the latter.

The section dealing with flowering plants differs only from similar sections in existing syllabuses by being more explicit, in order to limit the amount of morphological knowledge required. Suggestions are also given for plant physiological experiments, and in this connexion the sub-committee would like to record its gratitude to one examining body for the lead given to the sub-committee. The study of other plant organisms is reduced to Spirogyra, Mucor and yeast, although the roles played by bacteria in Nature are mentioned in the general biological section.

Ecology has not been neglected, though it is a very debatable point as to whether it is worth while for the examiner to set questions on this subject at the School Certificate stage. The opinion of the sub. committee is best summed up by the following extract from the syllabus :

"A knowledge of more than ONE habitat for plants and ONE for animals is not expected. It is desirable, however, that the same habitat be chosen for both plant and animal field-work so that the interrelations between plants and animals in the field may be appreciated. Answers to questions in this section must show clearly that the candidate has personally studied the actual habitat selected."

It is felt that neither evolution nor genetics is a suitable examination subject for boys and girls of this age. The following paragraph, however, appears in the general preamble to the syllabus :

"No questions will be set on Evolution but the idea of evolution should be taught and illustrated at relevant points in the course based on the syllabus. It is hoped that teachers will at least outline the evidences for evolution from classification (e.g. of vertebrates), from the oceurrence of fossils and from simple morphology. The fact that certain eharacters are hereditable could be included with the general discussion of reproduction."

\section{The Quetta Earthquake of May 3I, I935}

A

PRELIMINARY report by Mr. W. D. West on the Quetta earthquake of May 31, 1935, has been published within six months of its occurrence in the Records of the Geological Survey of India (69, 203-240 (1935)). Further study of the materials may provide a more detailed series of isoseismal lines, and the discussion of the seismographic evidence will no doubt throw light on the position of the region in which the movement began. Otherwise, we cannot expect that much will be added to the details contained in this interesting report.

As in many another great earthquake, the shock came with but slight warning from fore-shocks in the central area, though one of moderate intensity was felt at Kalat on April 25, and four others at Bostan (near Quetta) between the middle of March and the end of May. The great earthquake occurred at about 3.3 a.m. Madras time (May 30, 9.33 p.m., G.M.T.), an electric clock in the telegraph office (apparently at Quetta) having stopped at this time, which, within a fow seconds, agrees with the seismographic evidence.

The epicentral tract is about 68 miles long and 16 miles wide and runs in the direction $\mathrm{S} .15^{\circ} \mathrm{W}$. from Baleli (north-west of Quetta), through Dingar and Mastung to Mand-i-Haji, and includes the Shirinab valley to the west of the Mastung-Kalat road. Within this zone, the intensity of the shock was about 10 of the Rossi-Forel scale. The absence of damage to trees and to roads, except in the neighbourhood of streams, the fact that lamp-posts and telegraph-posts were not as a rule thrown down, and the rare injury to railway lines, show that the earth- quake fell far short of the intensity of the great earthquakes of Assam in 1897, Kangra in 1905 and Bihar in 1934. Moreover, the disturbed area was unusually small-approximately 105,000 square miles. Even if we make a considerable allowance for its occurrence at night, the earthquake must have been felt over an area that is insignificant compared with the areas of between $1 \frac{1}{2}$ and 2 million square miles disturbed by the three great earthquakes mentioned above.

The intensity of the shock faded away rapidly from the epicentral region. Though no definite estimate of the focal depth has yet been founded on the seismographic evidence, it is probable, as $\mathrm{Mr}$. West suggests, that the depth was less, rather than more, than five miles.

A number of after-shocks were felt-unfortunately an unknown number, for no one on the spot seems to have kept any record. Five or six severe shocks occurred within the first twenty-four hours after the earthquake. On June 1, there were strong shocks at about 1.30 and 5.30 a.m. The most violent of all occurred on June 2 at about 3 p.m., one that would certainly have been destructive in the lower part of Quetta if there had been any buildings left there to destroy.

The effects of the earth-movement on the ground were not of much importance. The mountain sides round Quetta, precipitous and for the most part of limestone, were scarred by the fall of immense masses of rock. A line of fissuring in the ground was traced, with occasional interruptions, from the south side of Chiltan to the neighbourhood of Kalat. Over the 